\title{
PENGARUH KUALITAS PELAYANAN, REPUTASI PERUSAHAAN, DAN KEPUASAAN NASABAH DALAM MENCIPTAKAN LOYALITAS NASABAH PADA PENGGUNAAN MOBILE BANKING DI PT BANK XYZ
}

\author{
Octario Edo Setyawan \\ Program Studi Magister Manajemen Universitas Tarumanagara \\ octarioedo14@gmail.com \\ Anas Lutfi \\ Program Studi Magister Manajemen Universitas Tarumanagara
}

\begin{abstract}
This study aims to analyze the quality of service, reputation and loyalty of customers to mobile banking user loyalty at Bank XYZ. In addition, it can provide valuable input for customers in maintaining and improving service quality and customer satisfaction. This research uses qualitative methods and is included in survey research. Data to be used is the primary data obtained through the distribution of questionnaires. This, in this study is a Bank XYZ loan. The number of surveys will be conducted on 122 people who have used mobile banking at Bank XYZ. According to Aritonang (2007), the minimum number of respondents is 5 times from the question point, that is $5 \times 22: 110$ obtained from the number of respondents is 122 . The research period is cross sectional where the data is done at one time. Time is done in the period April - May 2018. Data analysis is done using statistical analysis with multiple linear regression analysis with the help of SPSS program version 24.00. The results showed that customer satisfaction and satisfaction proved to have positive and positive impact on customer loyalty at PT Bank XYZ. Quality of service and customer satisfaction is very influential as much as $61.6 \%$ of customer loyalty. The company's reputation proved to have no effect on customer loyalty in PT Bank XYZ because it has a sig value $>0.05$.
\end{abstract}

Keywords : Quality of service, Reputation, customer satisfaction and customer loyalty

\section{PENDAHULUAN}

Dewasa ini dalam perkembangan teknologi, nasabah dalam melakukan kegiatan transaksi dalam perbankan tidak lagi hanya menggunakan cara tradisional dengan cara nasabah datang langsung ke bank dan mengantri tetapi sudah memanfaatkan teknologi seperti yang sudah diketahui saat ini dengan menggunakan sebuah alat bantu dalam bentuk aplikasi mobile banking ( $m$-banking). Sehingga nasabah dapat melakukan transaksi dimana pun dan kapan pun tidak terbatas oleh waktu dan tempat, sehingga tidak selalu transaksi perbankan nasabah harus datang ke bank melainkan dapat diakses realtime melalui mobile banking. Mobile banking pada umunya disebut M-Banking yang merupakan sebuah teknologi informasi berupa layanan aplikasi dari sebuah lembaga keuangan yang dimiliki oleh Bank untuk membantu nasabah dalam melakukan sejumlah transaksi keuangan yang dapat diakses langsung oleh nasabah melalui perangkat mobile seperti telepon seluler atau smartphone.

Menurut Undang-Undang No. 10 Tahun 1998 tentang perbankan disebutkan bahwa, Perbankan adalah segala sesuatu yang menyangkut tentang bank, mencakup kelembagaan, kegiatan usaha, serta cara dan proses dalam melaksanakan kegiatan usahanya dan Bank adalah badan usaha yang menghimpun dana dari masyarakat dalam bentuk simpanan dan menyalurkannya kepada masyarakat dalam bentuk kredit atau bentuk lainnya dalam rangka meningkatkan taraf hidup rakyat banyak. Bank itu sendiri merupakan salah satu badan yang sangat bergantung sekali dengan teknologi informasi (IT) untuk memperoleh, mengolah, dan 
menyampaikan informasi yang dibutuhkan oleh nasabahnya. Dan dalam bank sendiri, teknologi informasi terbagi dalam berbagai banyak jenis salah satunya yang banyak digunakan dan semakin eksis saat ini digunakan oleh masyarakat yakni mobile banking.

Ruang lingkup penelitian ini dibatasi hanya meneliti loyalitas nasabah pengguna mobile banking pada PT Bank XYZ yang ditinjau dari reputasi perusahaan, kualitas pelayanan dan kepuasaan nasabah (Studi survei nasabah Jakarta PT Bank XYZ). Tujuan dari penelitian yang dilakukan adalah untuk mengetahui variabel mana yang saja yang memiliki pengaruh terhadap variabel loyalitas nasabah sehingga agar kedepannya menjadi masukan untuk perusahaan yang penulis teliti agar dapat meningkatkan loyalitas nasabahnya.

\section{TINJAUAN PUSTAKA}

Mobile banking menurut Nurastuti (2011), istilah mobile banking dianggap berkaitan erat dengan pengertian fasilitas perbankan melalui komunikasi bergerak seperti handphone, dengan penyedian fasilitas yang hampir sama dengan ATM, kecuali mengambil uang cash. Sehingga dapat dikatakan mobile banking merupakan bagian dari digital banking.

Reputasi Perusahaan Paul A. Argenti dan Bob Druckenmiller (2004) mendefinisikan "reputasi perusahaan sebagai gabungan dari berbagai macam image yang mewakili suatu perusahaan". Yang mana reputasi ini dibangun sejak lama yang berdasarkan identitas perusahaan, kinerja perusahaan serta bagaimana masyarakat mempersepsikan perilaku perusahaan tersebut. Reputasi tentang suatu perusahaan ditangkap oleh publik (masyarakat) secara langsung maupun tidak langsung berdasarkan pengalaman dan informasi yang diterima. Reputasi perusahaan adalah persepsi orang luar secara keseluruhan terhadap karakteristik suatu perusahaan. Banyak peneliti dan pengamat strategi organisasi berpendapat bahwa reputasi perusahaan memainkan peranan dalam hubungan perusahaan dengan lingkungannya.

Kualitas Pelayanan sebagaimana dikutip dari Tjiptono (2008) menyatakan "kualitas pelayanan sebagai tingkat keunggulan yang diharapkan dan pengendalian atas keunggulan tersebut untuk memenuhi keinginan pelanggan". Dengan kata lain terdapat dua faktor utama yang mempengaruhi kualitas pelayanan, yakni pelayanan yang diharapkan dan pelayanan yang dipersepsikan. Kualitas pelayanan berkontribusi besar pada kepuasan pelanggan, retensi pelanggan, word of mouth, pembelian ulang, loyalitas pelanggan, pangsa pasar dan profitabilitas. Pelayanan bersifat non fisik (intangible) dan lebih merupakan proses yang dialami pelanggan secara subjektif, dimana aktivitas produksi dan konsumsi berlangsung pada saat yang bersamaan.

Kepuasan Nasabah, Menurut Tse dan Wilton sebagaimana dikutip dari Harcahyani (2010), kepuasan didefinisikan "sebagai respon pelanggan terhadap evaluasi diskrepansi / ketidaksesuaian yang dirasakan antara ekspektasi sebelumnya (atau beberapa norma kerja lain) dan kinerja aktual dari produk sebagaimana yang dirasakan setelah pengkonsumsiannya”. Menurut Wilkie sebagaimana dikutip dari Harcahyani (2010) kepuasan di definisikan "sebagai suatu tanggapan emosional pada evaluasi terhadap pengalaman konsumen atas suatu produk dan jasa konsumen suatu atau jasa".

E-servcie Quality, Menurut Zeithaml et, al., (2002), dalam lingkungan online, service quality dedifinisikan sebagai perpanjangan dari website yang memfasilitasi keefisiensian dan keefektivitasan dalam berbelanja, membeli, dan memyampaikan produk atau jasa. Dimensi $e$ service quality dapat dikelompokan menjadi 5 yaitu, fullfilment, efficiency, security, responsiveness, dan contact (Molapo, 2008; Quan, 2010; Wu et al, 2012).

Loyalitas nasabah, Menurut Oliver (1997), loyalitas adalah "A deeply held commitment to rebuty or repatroinize a preffed product / service consistenly in the future, thereby, causing repetitive same brand or same brand set purchasing, despite situational influences and marketing efforts having the potential to cause switching behavior." Artinya : kesetiaan merupakan suatu komitmen mendalam untuk membeli kembali suatu produk atau jasa secara 
konsisten di masa yang akan datang seperti terhadap merek yang sama atau pembelian terhadap merek yang sama dengan mengasampingkan usaha-usaha pemsar dalam mengubah perilaku tersebut.

Kerangka Pemikiran, berdasarkan penjelasan teori yang sudah dijelaskan sebelumnya, terdeteksi secara konseptual tentang keterkaitan kualitas pelayanan, reputasi perusahaan dan kepuasan nasabah serta dampaknya pada loyalitas nasabah.

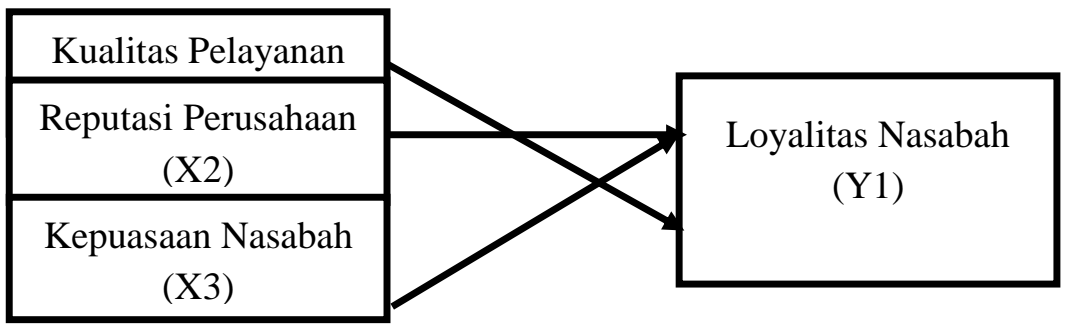

Hipotesis Penelitian, menurut Sugiyono (2005), hipotesis adalah jawaban sementara terhadap suatu rumusan masalah. dikatakan sementara karena jawaban yang diberikan baru didasarkan pada teori yang relevan, belum didasarkan pada fakta-fakta empiris yang diperoleh melalui pengumpulan data dan analisis data.

H1 = Terdapat pengaruh yang signifikan Service Quality terhadap loyalitas dalam penggunaan mobile banking

$\mathrm{H} 2$ = Terdapat pengaruh yang signifikan Reputasi perusahaan terhadap loyalitas dalam penggunaan mobile banking

$\mathrm{H} 3$ = Terdapat pengaruh yang signifikan kepuasaan terhadap loyalitas dalam penggunaan mobile banking

\section{METODOLOGI PENELITIAN}

Penelitian ini menggunakan data primer. Data dikumpulkan dengan teknik penyebaran kuesioner, yaitu dengan memberikan pernyataan-pernyataan tertulis kepada responden. Selanjutnya responden memberikan tanggapan atas pernyataan yang diberikan dengan lima pilihan yang diberikan oleh penulis. Kuesioner ini bersifat tertutup di mana jawabannya sudah tersedia. Kuesioner dirancang untuk pertanyaan yang menyangkut reputasi perusahaan, dimensi E-service quality (Fullfilment, Efficiency, Security, Responsiveness, Contact), kepuasan nasabah dan loyalitas nasabah. Dalam penelitian teknik penyebaran kuesioner ini menggunakan teknik pengukuran skala Likert. Skala Likert adalah sebuah bentuk skala yang akan mengindikasikan jawaban dari para responden setuju atau tidak setuju atas pernyataan mengenai suatu obyek. Skala inilah yang memberikan angka atau nilai terhadap suatu obyek, sehingga karakteristik yang terdapat pada obyek tersebut dapat diukur.

Analisis data yang digunakan pada penulisan ini adalah menggunakan analisis statistik yaitu dengan analisis regresi linear berganda dengan bantuan program SPSS versi 24.00. Namun, sebelum melakukan analisis regresi berganda, terlebih dahulu dilakukan pengujian Instrumen, statistik deskriptif, dan asumsi klasik: uji normalitas, uji multikolinearitas, dan uji heteroskedastisitas.

HASIL DAN PEMBAHASAN

Uji Validitas dan Realibilitas

Tabel Uji Validtas

\begin{tabular}{|c|c|c|}
\hline Indikator & $\begin{array}{c}\text { Corrected Item - Total } \\
\text { Correlation }\end{array}$ & Keterangan \\
\hline ES1 & 0,729 & Valid \\
\hline
\end{tabular}




\begin{tabular}{|c|c|c|}
\hline ES2 & 0,697 & Valid \\
\hline ES3 & 0,737 & Valid \\
\hline ES4 & 0,690 & Valid \\
\hline ES5 & 0,720 & Valid \\
\hline ES6 & 0,680 & Valid \\
\hline ES7 & 0,764 & Valid \\
\hline ES8 & 0,789 & Valid \\
\hline ES9 & 0,769 & Valid \\
\hline ES10 & 0,686 & Valid \\
\hline ES11 & 0,680 & Valid \\
\hline ES12 & 0,655 & Valid \\
\hline RP1 & 0,776 & Valid \\
\hline RP2 & 0,776 & Valid \\
\hline KEP1 & 0,717 & Valid \\
\hline KEP2 & 0,831 & Valid \\
\hline KEP3 & 0,776 & Valid \\
\hline KEP4 & 0,901 & Valid \\
\hline LOY1 & 0,703 & Valid \\
\hline LOY2 & 0,697 & Valid \\
\hline LOY3 & 0,709 & Valid \\
\hline LOY4 & 0,697 & Valid \\
\hline
\end{tabular}

Dari hasil uji validitas keempat varibel tersebut menunjukan bahwa nilai corrected item total correlation semua indikator pada setiap variabel yang digunakan oleh peneliti memiliki angka yang lebih besar dari 0,3, sehingga dapat disimpulkan bahwa semua indikator dari masing-masing variabel tersebut dinyatakan valid.

Tabel Uji Realibilitas

\begin{tabular}{|c|c|c|}
\hline Variabel & Cronbach Alpha & Keterangan \\
\hline Kualitas Pelayanan & 0,934 & Realibel \\
\hline Reputasi Perusahaan & 0,874 & Realibel \\
\hline Kepuasan Nasabah & 0,914 & Realibel \\
\hline Loyalitas Nasabah & 0,856 & Realibel \\
\hline
\end{tabular}

Sementara hasil dari uji realibilitas yang dilakukan pada seluruh variabel memiliki Cronbach Alpha diatas 0,7. Sehingga dapat disimpulkan bahwa keempat 4 varibel yang penulis digunakan sebagai bahan penelitian dinyatakan realibel.

Tabel hasil uji regresi berganda

\begin{tabular}{|c|c|c|c|}
\hline Variabel & $\begin{array}{c}\text { Standardized } \\
\text { Coefficients }\end{array}$ & $\mathbf{t}$ & sig \\
\hline Kualitas Pelayanan & 0,344 & 2,900 & 0,004 \\
\hline Reputasi Perusahaan & 0,142 & 1,693 & 0,093 \\
\hline Kepuasaan Nasabah & 0,362 & 3,177 & 0,002 \\
\hline
\end{tabular}

Hasil uji regresi linier berganda di atas menunjukan bahwa nilai koefisien regresi (b) yang paling besar adalah nilai service quality yaitu sebesar 0,387 , selanjutnya diikuti oleh variabel kepuasan nasabah sebesar 0,357, dan terakhir reputasi perusahaan sebesar 0,138. 
Berdasarkan table di atas dapat dirumuskan persamaan regresi untuk model tersebut sebagai berikut :

$$
\mathrm{LP}=0.486+0.387 \mathrm{SQ}+0.138 \mathrm{RP}+0.357 \mathrm{KP}
$$

\section{Uji Hipotesis}

\begin{tabular}{|c|c|c|c|}
\hline Variabel & $\begin{array}{c}\text { Standardized } \\
\text { Coefficients }\end{array}$ & $\mathbf{t}$ & sig \\
\hline Kualitas Pelayanan & 0,344 & 2,900 & 0,004 \\
\hline Reputasi Perusahaan & 0,142 & 1,693 & 0,093 \\
\hline Kepuasaan Nasabah & 0,362 & 3,177 & 0,002 \\
\hline
\end{tabular}

Hasil uji t model pada tabel diatas, menjelaskan bahwa variabel Kualitas Pelayanan memiliki nilai signifikan sebesar 0,004 $<0,05$ sehingga dapat diartikan bahwa adanya pengaruh langsung antara Kualitas Pelayanan terhadap Loyalitas Nasabah. Besarnya pengaruh Kualitas Pelayanan terhadap Loyalitas Nasabah adalah sebesar 0,344 atau 34,4\%.

Selanjutnya, untuk variabel Reputasi menghasilkan nilai signifikan sebesar 0,093 > 0,05 sehingga dapat diartikan bahwa tidak terdapat pengaruh langsung antara Reputasi perusahaan terhadap Loyalitas nasabah. Besarnya pengaruh Reputasi terhadap loyalitas nasabah adalah sebesar 0,142 atau $14,2 \%$.

Sedangkan, untuk variabel Kepuasan menghasilkan nilai signifikan sebesar 0,002 < 0,05 sehingga dapat diartikan bahwa adanya pengaruh langsung antara Kepuasan nasabah terhadap Loyalitas nasabah. Besarnya pengaruh Reputasi terhadap loyalitas nasabah adalah sebesar 0,362 atau $36,2 \%$.

\section{KESIMPULAN DAN SARAN Kesimpulan}

Pertama, faktor - faktor yang berpengaruh signifikan terhadap Loyalitas Nasabah dalam penggunan mobile banking adalah variabel kualitas pelayanan yang terdiri dari dimensi $e$ service quality : fullfillment, efficiency, security, responsiveness dan contact, adapun variabel lainnya yang signifikan berpengaruh yaitu variabel kepuasan nasabah dimana kedua variabel tersebut memiliki nilai sig $<0.05$. Kedua, variabel reputasi perusahaan merupakan variabel yang tidak memiliki pengaruh terhadap loyalitas nasabah, dikarenakan variabel tersebut mempunyai nilai signifikan diatas $>0,05$. Ketiga, variabel kepuasaan nasabah merupakan variabel yang paling besar mempengaruhi loyalitas nasabah pengguna mobile banking dengan nilai sig sebesar 0,02 dibandingkan variabel lainnya. Keempat, variabel kualitas pelayanan merupakan variabel yang paling rendah dalam memberikan pengaruh terhadap loyalitas nasabah dengan nilai signifikan sebesar 0,04 .

\section{Saran}

Berdasarkan analisa dan pembahasan dalam penelitian ini, maka saran yang dapat diberikan untuk PT Bank XYZ adalah sebagai berikut :

1. Kualitas pelayanan secara efektif dan signifikan dapat meningkatkan meningkatkan loyalitas nasabah. Untuk itu, managemen disarankan untuk mempertahankan kualitas pelayanan dengan terus meningkatkan kualitas teknologi yang disediakan oleh pihak Bank dan selain itu meningkatkan juga kualitas sumber daya manusianya agar pelayanan yang diberikan dari hulu ke hilir terjaga kualitasnya, menjaga kepercayaan konsumen dengan tidak mengecewakan nasabah dan selalu memenuhi janji pada konsumen. 
Elemen-elemen tersebut dapat meningkatkan loyalitas nasabah yang akan berdampak pada meningkatnya kepuasan pelanggan pada Bank XYZ.

2. Kepuasan nasabah secara efektif dan siginfikan dapat meningkatkan loyalitas nasabah. Untuk itu, pihak managemen diharapkan dapat meningkatkan elemen-elemen pendukung agar kepuasan nasabah dapat terjaga sehingga nasabah-nasabah menjadi loyal dengan terus memperhatikan kepuasan pelanggan.

3. Reputasi perusahaan tidak memberikan efek langsung terhadap loyalitas nasabah, Didukung dengan bukti dari hasil penelitian. Sehingga diharapkan pihak manajemen dapat terus meningkatkan reputasi perusahaannya, karena apabila reputasi perusahaan baik namun tidak sejalan dengan kualitas pelayanan yang diberikan maka akan berakibat domino juga terhadap reputasi perusahaan yang akan menjadi buruk.

\section{DAFTAR PUSTAKA}

Argenti, Paul dan Bob Druckenmiller. (2004). Reputation and the Corporate Brand. Corporate Reputation Review, Vol 6, No 4, pp 368-374.

Aritonang R., Lerbin (2007). Riset Pemasaran Teori dan Praktik. Bogor : Ghalia Indonesia. Harcahyani Grestiyaning. (2010). Analisis Kualitas Pelayanan Terhadap Kepuasan Pasien yang Dimoderasi Oleh Variabel Nilai. Tesis Universitas Pembangunan Veteran Nasional.

Molapo, M, N. (2008). An Assessment of internet banking service quality. Johannesburg: University of Johannesburg.

Nurastuti, Wiji. (2011). Teknologi Perbankan. Yogyakarta : Graha Ilmu.

Oliver, R.L, (1997). Satisfication : A behavioral perspective on the customer. New york : MCGraw Hill.

Quan, Sun. (2010). The Relationship Among E-Service Quality, System Quality, Information Quality and Customer Loyalty : An Empirical Study of Internet Banking In China. Global Journal of Management and Business Research, 10 (7), 27-33.

Sugiyono (2005). Metode Penelitian Bisnis. Bandung : CV. Alfabeta.

Tjiptono, Fandy. (2008). Strategi Bisnis Pemasaran. Yogyakarta: Andi.

Wu, Y.L., Tao, Y.H., dan Yang, P.C. (2012). Learning From The past and Present : Measuring Internet Banking Service Quality, Service Industry Journal, 32 (2).

Zeithaml, V.A., Parasuraman, A. and Malhotra, A. (2002). Service quality delivery through Websites: a critical review of extant knowledge. Journal of the Academic of Marketing Science, 30 (4), 362 -75. 
